\title{
Accuracy of partially edentulous arch impressions obtained from different alginates and storage times
}

\author{
Lucas de Oliveira Tomaselli', Rafael Pino Vitti' ${ }^{2}$ Marcus Vinicius Loureiro Bertolo ${ }^{3}$, Gabriel Abuna ${ }^{3}$, \\ William Cunha Brandt ${ }^{4}$, Mário Alexandre Coelho Sinhoreti ${ }^{5}$
}

${ }^{1}$ DDS, MSc student, University of Campinas, Piracicaba Dental School, Department of Restorative Dentistry, Piracicaba, SP, Brazil ${ }^{2}$ DDS, MSc, PhD, Associate Professor, University of Taubaté, School of Dentistry, Department of Prosthodontics, Taubaté, SP, Brazil ${ }^{3}$ DDS, MSc, PhD student, University of Campinas, Piracicaba Dental School, Department of Restorative Dentistry, Piracicaba, SP, Brazil ${ }^{4}$ DDS, MSc, PhD, Associate Professor, University of Santo Amaro, School of Dentistry, Department of Implantology, São Paulo, SP, Brazil ${ }^{5}$ DDS, MSc, PhD, Full Professor, University of Campinas, Piracicaba Dental School, Department of Restorative Dentistry, Piracicaba, SP, Brazil

Received for publication: November 23, 2016 Accepted: May 16, 2017

Correspondence to:

Marcus Vinicius Loureiro Bertolo University of Campinas

Avenida Limeira, 901

Piracicaba - SP

CEP: $13414-903$

Phone/Fax: +55 21 99856-9898

e-mail: marcusbertolo@hotmail.com

\begin{abstract}
Purposes: This study aimed to assess the dimensional accuracy of five commercial alginates verified in stone casts. Methods: Each alginate impression (Cavex ColorChange, Cavex Holland BV; Jeltrate Plus, Dentsply; Hydrogum, Zhermack; Kromopan 100, Lascod; Ezact Kromm, Vigodent) was performed on partially edentulous standard stainless steel mandibular arch cast with reference points on teeth $33,43,37$ and 47 . On the stainless steel cast, the anteroposterior (33-37 and 43-47) and transverse (33-43 and 37-47) distances were measured in a stereomicroscope at 30x magnification and $0.5 \mu \mathrm{m}$ accuracy. The distances between these points were measured three times, obtaining an average, which was analyzed statistically and compared with the distances obtained from the stone casts. For each alginate the casts were poured gypsum $(n=5)$ immediately and after a period of 1 , 2,3 and 5 days of the impression procedure. Results: The dimensional accuracy values of stone and stainless steel casts were analyzed statistically by two-way ANOVA and Tukey's test $(a=0.05)$. The results showed significant differences between the alginates; however, no differences in dimensional accuracy were found among the different storage times of alginate impression. Conclusions: It can be concluded that the alginate impressions can be stored for up to 5 days.
\end{abstract}

Keywords: Dimensional Measurement Accuracy; Dental Impression Material; Mandibular Prosthesis.

\section{Introduction}

Impression materials are used in Dentistry to create accurate casts of buccal tissues for pre-treatment planning, fabrication of prostheses, and post-treatment records. They can be classified in inelastic or elastic materials, which return to their initial form after be removed from mouth due to elastic recovery, and also according to chemical reaction (irreversible or reversible). The alginate (irreversible hydrocolloid) is an impression material that appeared in Dentistry on '40s, when the agar supplies (reversible hydrocolloid) became insufficient due to the World War II. The impression materials must copy the anatomy of buccal tissues and remain dimensionally stable. Alginate is an impression material widely used in in Dentistry and its popularity is due to the easy manipulation, low cost, and its hydrophilicity ${ }^{1}$.

Satisfactory results are obtained with stone casts made by alginate impression and used for the preparation of orthodontic studies, making plackers mouth guard, and dental 
prosthesis ${ }^{2,3}$. Alginates are commonly used as powder and water. The powder contains, in weight, diatomaceous earth $(60 \%)$ and oxide zinc ( $4 \%)$ as filler particles, calcium sulfate $(16 \%)$ as reactor, sodium or potassium alginates $(15 \%)$ as soluble alginate, potassium titanium fluoride (3\%) as accelerator (gypsum hardener), and sodium phosphate $(2 \%)$ as retarder ${ }^{1}$. The good dimensional accuracy is required for a reliable copy of the molded anatomy. Alginates are commercially available at pre-dosed or customized packages, bulk, bags, pots, sachets, daypacks or private label ${ }^{4}$. The gelation process is a sol-gel reaction, where at the contact with water, the sodium alginate (or potassium alginate) reacts with calcium sulfate, resulting in a molecular network of crosslinking (alginate gel) ${ }^{5}$.

The hydrocolloids are $85 \%$ water approximately, then they are submitted to distortion due to the expansion, that occurs with humidity absorption (imbibition) or shrinkage due to water loss by syneresis or evaporation ${ }^{6,7}$. These processes (expansion/shrinkage) are mainly related to the storage medium of the alginate impression. Another factors like the kind of the tray used at the impression, the material handling, disinfection process, temperature variance, quantity and quality of the chemical components present at alginate powder, also could interfere at the stability and dimensional accuracy ${ }^{1}$.

Some studies ${ }^{8-12}$ recommend that alginate impressions must be poured as fastest as possible, avoiding the excessive air exposure (syneresis and evaporation). If the pouring procedure is not possible, the most recommended step is to keep the impression at $100 \%$ humidity environment in order to preserve the hydric balance within the material ${ }^{13}$. Following the manufacturer's recommendations, the casts could be poured until $12 \mathrm{~h}$ after the alginate gelation. Shaba et al.10 (2007) suggested that this time must be reduced until 30 minutes contrary to other authors. Sedda et al..$^{9}$ (2008) concluded that alginate impressions remains dimensionally stables after $24 \mathrm{~h}$, one of this was Hydrogum (Zhermack) which was the only one that remains dimensionally acceptable to be poured after $72 \mathrm{~h}$. Some alginates commercially available may be stored up to five days without jeopardizing the stability and dimensional accuracy according the manufacturer's recommendations, but this information is questionable, since there is no consensus about $\mathrm{it}^{8-12}$. Moreover, there is no study with a cast representing a clinical situation to evaluate dimensional stability and/or accuracy.

Due to these properties, the storage recommendations of this material, it appears the question if it is possible to retain the original dimensions after 5 days without interfere with the dimensional accuracy. The aim of this study was to evaluate the dimensional accuracy of five commercial alginates on casts poured at different times of a partially edentulous mandibular arch. The hypothesis is that the stone casts obtained immediately after the impression presents less dimensional accuracy alteration.

\section{Materials and methods}

Five commercial alginates impression materials were used: Cavex ColorChange-CH (Cavex Holland BV, Haarlem, North Holland, Netherlands), Jeltrate Plus-JT (Dentsply, Petrópolis, RJ, Brazil), Hydrogum-HY (Zhermack, Badia Polesine, Rovigo, ltaly), Kromopan 100-KR (Lascod, Florence, Tuscany, Italy) and Ezact
Kromm-EZ (Vigodent, Rio de Janeiro, RJ, Brazil).

In order to simulate a clinical condition to obtain the impressions, all procedures were realized on a standard stainless steel cast representing a partially edentulous mandibular arch with reference points 14 on the left and right canines (33 and 43), and left and right second molars (37 and 47). The anteroposterior (33$37 ; 35.22 \mathrm{~mm}$ and $43-47 ; 35.06 \mathrm{~mm})$ and transverse $(33-43 ; 25.06$ $\mathrm{mm}$, and $37-47 ; 50.01 \mathrm{~mm}$ ) distances were measured by Olympus Measuring Microscope STM (Olympus Optical Co., Tokyo, Kanto, Japan) at 30x magnification and $0.5 \mu \mathrm{m}$ accuracy.

The ocular lens were adjusted to the inner vertical and horizontal border of the reference point and compared to the opposite reference point, at a linear trajectory ${ }^{15}$. Every distance was measured three times by a single calibrated operator, obtaining an average, which was compared to the stone casts.

Metal stock trays I-3 (Tecnodent, Bologna, Emilia-Romagna, Italy) were used for the impression procedure. The alginates were mixed following the manufacturer's instructions at a temperature and humidity controlled environment $\left(23^{\circ} \mathrm{C} \pm 2{ }^{\circ} \mathrm{C}\right.$ and $50 \% \pm$ $10 \%) 16$, controlling the factors that lead to dimensional alteration. After the impression materials handling, they were placed into tray to impression of the stainless steel cast. The set tray/impression material was positioned on the stainless steel cast from posterior to anterior direction. After the gelation, the tray was carefully removed with a single and vertical movement. Metallic gadgets were adapted to the trays, which were joined to pneumatic equipment, to standardize the detachment movement of the tray from the stainless steel cast in order to avoid distortions in the mold ${ }^{16}$.

Dental stone type IV (Durone, Dentsply, Petrópolis, RJ, Brazil) was used in a water/powder ratio of $28.5 \mathrm{~mL} / 150 \mathrm{~g}$ for stone cast pouring. The stone casts were poured immediately and 1,3 or 5 days after impression. The stored groups were maintained in a humidifier with $100 \%$ relative humidity and room temperature $\left(23^{\circ} \mathrm{C} \pm 2^{\circ} \mathrm{C}\right)$. Five models were obtained $(\mathrm{n}=5)$ for each commercial alginate and storage condition ${ }^{13,16-20}$. After dental stone set, the stone casts were evaluated for the presence of pores or other defects, being discarded those who present any defect in one of the reference points.

As in the stainless steel cast, three readings were performed by a single calibrated operator at each of the four distances between the dental elements (33-43, 33-37, 43-47 and 37-47), obtaining the average of each distance. All readings occurred in the same environment with the same temperature and humidity.

The original values of dimensional change were converted into percentage, considering as original the measures stainless steel cast. If negative, indicate that there was a decrease of distances (shrinkage) and, if positive, indicate an increase (expansion). All data were submitted to normality test (Kolmogorov-Smirnov) and analyzed statistically by 2-way ANOVA (material x storage time) for each distance and the means were compared by Tukey's test $(\alpha=0.05)$.

\section{Results}

Table 1 shows that stone casts poured for distance 37-47 presented no statistical difference in dimensional accuracy for 2-5 
days of storage times ( $p>0.05$ ), except for HY (2 days) group $(p<0.05)$, which was statistically similar to HY (1 day) group $(p>0.05)$. The lowest values of dimensional alteration were found for impressions poured with dental stone immediately or after 1 day of storage times. For the other transverse distance (33-43) similar values of dimensional accuracy were found for all storage times (Table 2) $(\mathrm{p}>0.05)$. In general, for both transverse distances all alginates impressions showed stone casts with expansion (positive values) and similar dimensional alteration, except for 37-47 distance poured immediately and after 1 day, where HY presented the highest means of dimensional alteration and for 33-43 distance poured all periods of time, where JT showed the lowest means of dimensional alteration $(\mathrm{p}<0.05)$. Still, Table 2 shows also that JT did not differ statistically from EZ, $\mathrm{CH}$, and $\mathrm{HY}$ for 1 day $(\mathrm{p}>0.05)$.

Table 1 - Mean of dimensional alteration and SD (\%) of stone casts obtained with different alginates and poured in different periods of time (distance 37-47).

\begin{tabular}{lccccc}
\hline & Immediately & 1 day & 2 days & 3 days & 5 days \\
\hline HY & $0.108 \pm 0.013 \mathrm{a}, \mathrm{C}$ & $0.239 \pm 0.003 \mathrm{a}, \mathrm{BC}$ & $0.348 \pm 0.018 \mathrm{~b}, \mathrm{~B}$ & $0.418 \pm 0.008 \mathrm{a}, \mathrm{A}$ & $0.371 \pm 0.018 \mathrm{a}, \mathrm{A}$ \\
$\mathrm{KR}$ & $-0.036 \pm 0.017 \mathrm{bc}, \mathrm{B}$ & $0.166 \pm 0.011 \mathrm{~b}, \mathrm{~B}$ & $0.421 \pm 0.024 \mathrm{a}, \mathrm{A}$ & $0.391 \pm 0.025 \mathrm{ab}, \mathrm{A}$ & $0.367 \pm 0.021 \mathrm{a}, \mathrm{A}$ \\
$\mathrm{CH}$ & $-0.081 \pm 0.018 \mathrm{bc}, \mathrm{B}$ & $0.115 \pm 0.014 \mathrm{bc}, \mathrm{B}$ & $0.371 \pm 0.018 \mathrm{ab}, \mathrm{A}$ & $0.347 \pm 0.020 \mathrm{ab}, \mathrm{A}$ & $0.392 \pm 0.030 \mathrm{a}, \mathrm{A}$ \\
$\mathrm{EZ}$ & $-0.005 \pm 0.009 \mathrm{~b}, \mathrm{~B}$ & $0.017 \pm 0.008 \mathrm{~cd}, \mathrm{~B}$ & $0.308 \pm 0.009 \mathrm{~b}, \mathrm{~A}$ & $0.300 \pm 0.024 \mathrm{~b}, \mathrm{~A}$ & $0.301 \pm 0.019 \mathrm{a}, \mathrm{A}$ \\
$\mathrm{JT}$ & $-0.127 \pm 0.014 \mathrm{c}, \mathrm{B}$ & $-0.013 \pm 0.005 \mathrm{~d}, \mathrm{~B}$ & $0.374 \pm 0.028 \mathrm{ab}, \mathrm{A}$ & $0.331 \pm 0.015 \mathrm{ab}, \mathrm{A}$ & $0.305 \pm 0.14 \mathrm{a}, \mathrm{A}$ \\
\hline
\end{tabular}

Data with different lowercase letters in column and capital letters in row are statistically different $(\mathrm{p}<0.05)$.

Table 2 - Mean of dimensional alteration and SD (\%) of stone casts obtained with different alginates and poured in different periods of time (distance 33-43).

\begin{tabular}{lccccc}
\hline & Immediately & 1 day & 2 days & 3 days & 5 days \\
\hline HY & $0.122 \pm 0.014 \mathrm{a}, \mathrm{A}$ & $0.138 \pm 0.018 \mathrm{~b}, \mathrm{~A}$ & $0.240 \pm 0.022 \mathrm{a}, \mathrm{A}$ & $0.154 \pm 0.016 \mathrm{a}, \mathrm{A}$ & $0.253 \pm 0.034 \mathrm{a}, \mathrm{A}$ \\
$\mathrm{KR}$ & $0.173 \pm 0.020 \mathrm{a}, \mathrm{A}$ & $0.325 \pm 0.014 \mathrm{a}, \mathrm{A}$ & $0.266 \pm 0.028 \mathrm{a}, \mathrm{A}$ & $0.197 \pm 0.033 \mathrm{a}, \mathrm{A}$ & $0.241 \pm 0.012 \mathrm{a}, \mathrm{A}$ \\
$\mathrm{CH}$ & $0.124 \pm 0.005 \mathrm{a}, \mathrm{A}$ & $0.107 \pm 0.021 \mathrm{~b}, \mathrm{~A}$ & $0.253 \pm 0.028 \mathrm{a}, \mathrm{A}$ & $0.246 \pm 0.037 \mathrm{a}, \mathrm{A}$ & $0.216 \pm 0.044 \mathrm{a}, \mathrm{A}$ \\
$\mathrm{EZ}$ & $0.095 \pm 0.012 \mathrm{a}, \mathrm{A}$ & $-0.056 \pm 0.019 \mathrm{c}, \mathrm{A}$ & $0.160 \pm 0.024 \mathrm{a}, \mathrm{A}$ & $0.266 \pm 0.033 \mathrm{a}, \mathrm{A}$ & $0.130 \pm 0.013 \mathrm{a}, \mathrm{A}$ \\
$\mathrm{JT}$ & $-0.094 \pm 0.036 \mathrm{~b}, \mathrm{~A}$ & $0.010 \pm 0.016 \mathrm{bc}, \mathrm{A}$ & $-0.029 \pm 0.036 \mathrm{~b}, \mathrm{~A}$ & $-0.056 \pm 0.012 \mathrm{~b}, \mathrm{~A}$ & $-0.050 \pm 0.010 \mathrm{~b}, \mathrm{~A}$ \\
\hline
\end{tabular}

Data with different lowercase letters in column and capital letters in row are statistically different $(\mathrm{p}<0.05)$.

In general, the results were similar in the 33-37 anteroposterior distance (Table 3). No statistical difference were found in dimensional accuracy for all storage times $(p>0.05)$, except for KR (Immediately) and JT (Immediately, 1, and 2 days) groups which presented lower dimensional alteration than others different pouring times for each alginate group $(\mathrm{p}<0.05)$.
On other hand, for 43-47 anteroposterior distance (Table 4), no statistical difference were found in dimensional accuracy for all storage times for $\mathrm{KR}, \mathrm{CH}$, and $\mathrm{EZ}$ groups ( $\mathrm{p}>0.05)$, but $\mathrm{HY}$ alginate showed highest dimensional alteration for immediate pouring time and JT lowest dimensional alteration mean values for 3 and 5 days of pouring times $(\mathrm{p}<0.05)$.

Table 3 - Mean of dimensional alteration and SD (\%) of stone casts obtained with different alginates and poured in different periods of time (distance 33-37).

\begin{tabular}{lccccc}
\hline & Immediately & 1 day & 2 days & 3 days & 5 days \\
\hline HY & $-0.256 \pm 0.035 a b, A$ & $-0.298 \pm 0.044 \mathrm{a}, \mathrm{A}$ & $-0.215 \pm 0.033 \mathrm{~b}, \mathrm{~A}$ & $-0.223 \pm 0.037 \mathrm{~b}, \mathrm{~A}$ & $-0.201 \pm 0.017 \mathrm{~b}, \mathrm{~A}$ \\
KR & $-0.044 \pm 0.009 \mathrm{~b}, \mathrm{~B}$ & $-0.209 \pm 0.025 \mathrm{a}, \mathrm{A}$ & $-0.228 \pm 0.027 \mathrm{~b}, \mathrm{~A}$ & $-0.229 \pm 0.020 \mathrm{~b}, \mathrm{~A}$ & $-0.297 \pm 0.019 \mathrm{~b}, \mathrm{~A}$ \\
$\mathrm{CH}$ & $-0.203 \pm 0.019 \mathrm{~b}, \mathrm{~A}$ & $-0.211 \pm 0.008 \mathrm{a}, \mathrm{A}$ & $-0.233 \pm 0.006 \mathrm{~b}, \mathrm{~A}$ & $-0.151 \pm 0.017 \mathrm{~b}, \mathrm{~A}$ & $-0.181 \pm 0.011 \mathrm{~b}, \mathrm{~A}$ \\
EZ & $-0.281 \pm 0.024 \mathrm{ab}, \mathrm{A}$ & $-0.339 \pm 0.005 \mathrm{a}, \mathrm{A}$ & $-0.238 \pm 0.033 \mathrm{~b}, \mathrm{~A}$ & $-0.289 \pm 0.021 \mathrm{~b}, \mathrm{~A}$ & $-0.242 \pm 0.033 \mathrm{~b}, \mathrm{~A}$ \\
JT & $-0.332 \pm 0.032 \mathrm{a}, \mathrm{B}$ & $-0.323 \pm 0.030 \mathrm{a}, \mathrm{B}$ & $-0.446 \pm 0.027 \mathrm{a}, \mathrm{B}$ & $-0.508 \pm 0.009 \mathrm{a}, \mathrm{A}$ & $-0.619 \pm 0.017 \mathrm{a}, \mathrm{A}$ \\
\hline
\end{tabular}

Data with different lowercase letters in column and capital letters in row are statistically different $(\mathrm{p}<0.05)$.

Table 4 - Mean of dimensional alteration and SD (\%) of stone casts obtained with different alginates and poured in different periods of time (distance 43-47).

\begin{tabular}{|c|c|c|c|c|c|}
\hline & Immediately & 1 day & 2 days & 3 days & 5 days \\
\hline $\mathrm{HY}$ & $-0.391 \pm 0.008 a, A$ & $-0.068 \pm 0.004$ bc,B & $-0.019 \pm 0.031 c, B$ & $-0.023 \pm 0.008 b, B$ & $-0.046 \pm 0.012 b, B$ \\
\hline $\mathrm{KR}$ & $-0.081 \pm 0.033 b, A$ & $-0.188 \pm 0.025 b, A$ & $-0.120 \pm 0.008 b c, A$ & $-0.082 \pm 0.013 b, A$ & $-0.093 \pm 0.018 a b, A$ \\
\hline $\mathrm{CH}$ & $-0.033 \pm 0.016 b, A$ & $-0.048 \pm 0.022 c, A$ & $-0.184 \pm 0.006 b, A$ & $-0.091 \pm 0.016 b, A$ & $-0.060 \pm 0.021 b, A$ \\
\hline$E Z$ & $-0.042 \pm 0.022 b, A$ & $-0.102 \pm 0.019 b c, A$ & $-0.086 \pm 0.012 b c, A$ & $-0.073 \pm 0.023 b, A$ & $-0.121 \pm 0.044 a b, A$ \\
\hline JT & $-0.488 \pm 0.046$ a,A & $-0.392 \pm 0.023 a, A B$ & $-0.375 \pm 0.040 a, A B$ & $-0.291 \pm 0.035 a, B C$ & $-0.216 \pm 0.023 a, C$ \\
\hline
\end{tabular}

Data with different lowercase letters in column and capital letters in row are statistically different $(p<0.05)$. 
Comparing the alginates, JT showed the worst dimensional stability for all pouring times $(\mathrm{p}<0.05)$ and did not differ from HY for immediate time in 43-47 distance $(p>0.05)$. However, for 33-37 distance JT presented the highest mean of dimensional alteration only for 2,3 , and 5 days of pouring times $(p<0.05)$. In contrast to transverse distances, both anteroposterior distances for all alginates and storage times showed stone casts with shrinkage (negative numbers) as compared to those of the stainless steel cast. Descriptive data summarization presents the behavior of the alginates in all distances along the time (Figure 1).

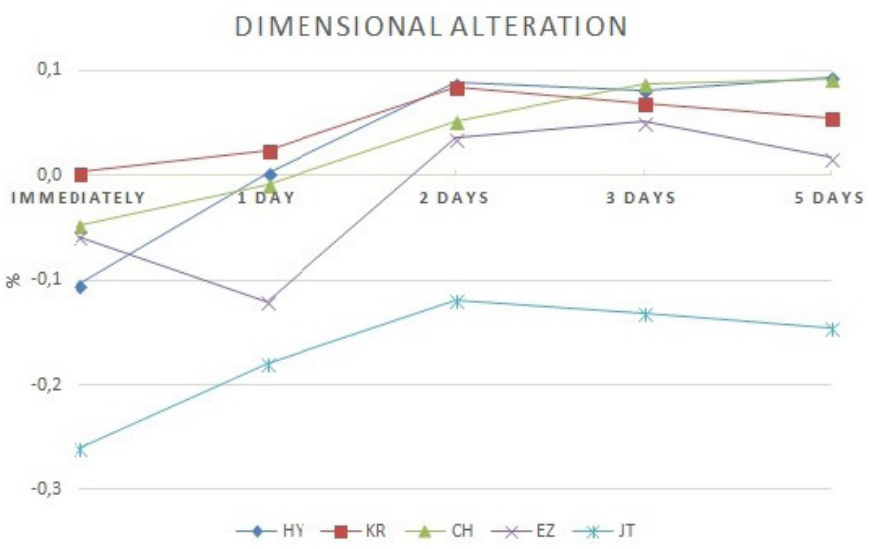

Fig. 1 - Frequency of periodontal sites.

\section{Discussion}

Anatomical dental stone casts, which accurately reproduce the shape of the teeth and adjacent buccal tissues, are used for many diagnostic and treatment purposes in Dentistry. A dimensionally accurate impression (negative mold) is essential for fabricating an accurate anatomical stone casts ${ }^{1}$.

Based on results of the current study, the hypothesis was rejected, since the stone casts poured immediately after impression procedure showed similar dimensional accuracy values than stone casts produced after different storage times in an environment with $100 \%$ relative humidity and room temperature $\left(23^{\circ} \mathrm{C} \pm 2^{\circ} \mathrm{C}\right)$ for $1,2,3$ or 5 days.

To verify any properties of the impression materials there are specifications as International Organization for Standardization (ISO) 1563:199021. These specifications use models, casts and matrices presenting regions which may be easily measured. Although the specifications provide the possibility to compare the dimensional stability of different alginates, the tests used in these statements differ from clinical reality ${ }^{17}$. The use of a standard stainless steel cast representing a partially edentulous mandibular arch in this study represents a situation routinely observed in clinical practice.

According to Faria et al. ${ }^{17}$ (2008) the molds made by alginate or elastomers impression material have similar dimensional accuracy. Thus, alginate may be considered highly accurate impression material. One advantage is that alginates are hydrophilic, while elastomers, except for the polyether and modified addition silicone, are hydrophobic1. Faria et al. ${ }^{17}$ (2008) suggest that alginates may replace the condensation (polydimethylsiloxanes) or addition (polyvinyl siloxanes) silicones in some clinical situations. This study corroborate with findings of the present study in terms of dimensional accuracy. Both specifications for alginate impression materials used in Dentistry to make impressions of the teeth and buccal tissues (ISO 1563:1990) ${ }^{21}$ contains no requirement for dimensional stability neither has any limits on dimensional changes. It is known in the literature for elastomeric impression materials that their dimensional change should be no more than $\pm 0.5 \%$ upon setting and after storage time ${ }^{16}$. Thus, the dental stone models made from alginate impressions used in this study poured up to 5 days showed dimensional changes within the limits recommended for elastomeric impression materials.

To obtain a good dimensional accuracy is required a rigid control of the factors that may compromise the dimensional stability of alginates, decreasing the effects of expansion and shrinkage ${ }^{11}$. In this study, besides the standardized ratio and handling of the impression material in an environment with temperature and humidity controlled, the molds were placed in humidifiers with rigid humidity control (100\%), decreasing the effects of syneresis and evaporation, responsible for alginate shrinkage, and imbibition, responsible for the expansion of the material. At first, the alginate has expansion due the excess of water added to handle the impression material. This initial expansion is compensate by alginate syneresis as a function of time due to the continued gelation process, which compresses the water onto the surface of gel structures. The syneresis may be highly accelerated in an environment with low water saturation ${ }^{8}$. In this study, the humidity was maintained in $100 \%$. Thus, the syneresis speed decreased and the alginate remained dimensionally stable up to 5 days. It was not possible to claim that the stone cast had expansion or shrinkage, because some areas (transverse distances) showed expansion due to tension release after the mold removal while others (anteroposterior distances) presented shrinkage due the syneresis towards the center of the alginate impression, besides of the posterior border of the mandibular tray is open, then does not occur adhesion between alginate and tray. Moreover, the setting expansion of stone casts might have compensated the shrinkage caused by alginate syneresis ${ }^{18}$. For this occurred is necessary that the stone cast expand uniformly in three dimensions, but using an open tray the stone does not uniformly expand toward the impression. The stone cast increases only in width and does not in height. Thus, stone cast does not become geometrically similar to the master model ${ }^{19}$.

The tilting movement during removal of the impression from the buccal cavity may also jeopardize dimensionally the alginate ${ }^{15}$. In the present study, the detachment movement was standardized in a vertical direction. Another responsible for the dimensional instability of the impression materials is the thermal contraction inherent the differences between buccal cavity and environment temperatures. The impression procedures and the mold storage were realized in an environment with standard temperature, which prevented or decreased the thermal contraction. This explains the excellent results found in this study to the alginate. However, clinically is not always possible to work in suitable environments 
and to control every these factors. Even some studies ${ }^{8,9,11}$ have no a rigid control of the factors that may compromise the dimensional changes in impression materials, which explains some studies where the alginate does not present good results of dimensional accuracy or the storage of alginate molds is not suitable for more than one day ${ }^{9,10}$. On the other hand, studies ${ }^{18,20}$ controlling the sample preparation procedures corroborate with results of this study. These studies did not show difference in the dimensional accuracy of stone casts made from different alginate impression materials and stored for different times up to 5 days ${ }^{18}$.

The differences in dimensional accuracy between alginates tested is related mainly with the different chemical compositions of materials such as, for instance, the amount and type of filler present in each material, the proportion of matrix/filler and the quality of the matrix components ${ }^{22,23}$. These factors should be considered when the properties of the alginate are evaluated, such as dimensional stability ${ }^{22}$. The largest dimensional change occurred in the anteroposterior distance, observed mainly in the JT alginate. It can be explained by bilateral adhesion of the impression material to tray when considering the transversal direction of the mold and only unilateral anteroposterior direction. The free end of the mold may offer less restrictive strength to shrinkage, allowing dimensional changes in anteroposterior distance ${ }^{16}$. Furthermore, the transverse distance 37-47 showed greater dimensional changes at 2, 3, and 5 days than stone casts poured immediately and 1 day (Table 1), but these dimensional changes were smaller than $\pm 0.5 \%$ which is recommended for high accuracy impression material as elastomeric impression materials ${ }^{16}$.

The optical measuring microscope provides greater accuracy than digital models $(0.5 \mu \mathrm{m}$ accuracy $)$ to evaluate dimensional stability. It is a methodology supported by $\mathrm{ISO}^{21}$ specification. However, this method does not represent a common clinical application and dimensional instability of small distances $(<$ $1.0 \mu \mathrm{m})$ are clinically insignificant in partially edentulous arch impressions, since the dental stone has a crystalline structure that could not reproduce such amount of detail ${ }^{5}$. Furthermore, the stone casts made from alginate tend to lose details in angle areas used as reference points in optical measuring microscope for measurement of the distances ${ }^{7,24}$.

A limitation of in vitro studies is that we could not evaluate the effect of any factors such as blood, saliva, and/or temperature difference between buccal cavity and room where the mold will be stored (thermal shrinkage) on the dimensional accuracy/stability of impression materials ${ }^{9,16}$. In this study, the accuracy of alginates was measured indirectly on dental stone casts. This situation avoid inaccuracies promoted by time of measurement in measuring microscope, since temperature, humidity, and storage time may compromise dimensional stability and accuracy of impression materials $\mathbf{s}^{1,9,16,20}$.

This methodology is valid in terms of clinical application since the conditions would not be highly controlled in a clinical situation and the impression material is always used together dental stone in prosthodontic treatment of partially edentulous patients. Thus, the prosthesis misfit is due to loss of accuracy and dimensional instability and these conditions are time-dependent distortion of the mold storage and poured stone cast ${ }^{24}$, since alginate polymerization shrinkage occurs toward the center of the mold and it is speculated that, under clinical conditions, expansion of the dental stone could compensate partly this shrinkage ${ }^{25}$. Some distances showed shrinkage (negative values) due to alginate gelation while others present expansion (positive values) due to expansion of the dental stone. The differences between stone casts and stainless steel cast presented positive and negative values, but in order to avoid false results (positive and negative values canceling each other out), the data were converted to absolute values ${ }^{11}$.

An accurate stone cast is important for the manufacturing of fixed or removable and total or partial prosthesis. Thus, the choice of impression material and storage time is relevant. The differences in dimensional accuracy between the alginates seemed to be due the differences in the chemical composition of each material. Alginate impressions can be stored up to 5 days before pouring with dental stone, since the factors responsible for dimensional instability of the material (humidity, temperature and correct powder/liquid ratio) be controlled.

\section{References}

1. Craig RG. Review of dental impression materials. Adv Dent Res. 1988 Aug;2(1):51-64.

2. Nassar U, Aziz T, Flores-Mir C. Dimensional stability of irreversible hydrocolloid impression materials as a function of pouring time: a systematic review. J Prosthet Dent. 2011 Aug;106(2):126-33. doi: 10.1016/S0022-3913(11)60108-X.

3. Wadhwa SS, Mehta R, Duggal N, Vasudeva K. The effect of pouring time on the dimensional accuracy of casts made from different irreversible hydrocolloid impression materials. Contemp Clin Dent. 2013 Jul;4(3):313-8. doi: 10.4103/0976-237X.118368.

4. Amalan A, Ginjupalli K, Upadhya N. Evaluation of properties of irreversible hydrocolloid impression materials mixed with disinfectant liquids. Dent Res J (Isfahan). 2013 Jan;10(1):65-73. doi: 10.4103/17353327.111795.

5. Rueggeberg FA, Beall FE, Kelly MT, Schuster GS. Sodium hypochlorite disinfection of irreversible hydrocolloid impression material. J Prosthet Dent. 1992 May;67(5):628-31.

6. Rubel SB. Impression materials: a comparative review of impression materials most commonly used in restorative dentistry. Dent Clin North Am. 2007 Jul;51(3):629-42, vi.

7. Walker MP, Burckhard J, Mittis DA, Williams KB. Dimensional change over time of extended storage alginate impression materials. Angle Orthod. 2010 Nov;80(6):1110-5. doi: 10.2319/031510-150.1.

8. Miller MW. Syneresis in alginate impression materials. Br Dent J. 1975 Dec 2;139(11):425-30.

9. Sedda M, Casarotto A, Raustia A, Borracchini A. Effect of storage time on the accuracy of casts made from different irreversible hydrocolloids. J Contemp Dent Pract. 2008 May 1;9(4):59-66.

10. Shaba OP, Adegbulugbe IC, Oderinu $\mathrm{OH}$. Dimensional stability of alginate impression material over a four hours time frame. Nig Q J Hosp Med. 2007 Jan-Mar;17(1):1-4.

11. Chen SY, Liang WM, Chen FN. Factors affecting the accuracy of elastometric impression materials. J Dent. 2004; 32, 603-9.

12. Kulkarni MM, Thombare RU. Dimensional changes of alginate dental impression materials-An in vitro study. J Clin Diagn Res. 2015; 9, ZC98102.

13. Imbery TA, Nehring J, Janus C, Moon PC. Accuracy and dimensional stability of extended-pour and conventional alginate impression materials. J Am Dent Assoc. 2010 Jan;141(1):32-9. 
14. Consani RLX, Domitti SS, Mesquita MF, Consani S. Influence of flask closure and flask cooling methods on tooth movement in maxillary dentures. J Prosthodont. 2006 Jul-Aug;15(4):229-34.

15. Boscato N, Consani RLX, Consani S, Del Bel Cury AA. Effect of investment material and water immersion time on tooth movement in complete denture. Eur J Prosthodont Restor Dent. 2005 Dec;13(4):164-9.

16. Vitti RP, da Silva MA, Consani RL, Sinhoreti MA. Dimensional accuracy of stone casts made from silicone-based impression materials and three impression techniques. Braz Dent J. 2013 Sep-Oct;24(5):498-502. doi: 10.1590/0103-6440201302334

17. Faria AC, Rodrigues RC, Macedo AP, Mattos Mda G, Ribeiro RF. Accuracy of stone casts obtained by different impression materials. Braz Oral Res. 2008 Oct-Dec;22(4):293-8.

18. Guiraldo RD, Moreti AF, Martinelli J, Berger SB, Meneghel LL, Caixeta $\mathrm{RV}$, et al. Influence of alginate impression materials and storage time on surface detail reproduction and dimensional accuracy of stone models. Acta Odontol Latinoam. 2015;28(2):156-61. doi: 10.1590/ S1852-48342015000200010.

19. Teraoka F, Takahashi J. Dimensional changes and pressure of dental stones set in silicone rubber impressions. Dent Mater. 2000
Mar;16(2):145-9.

20. Guiraldo RD, Borsato TT, Berger SB, Lopes MB, Gonini-Jr A, Sinhoreti MA. Surface detail reproduction and dimensional accuracy of stone models: influence of disinfectant solutions and alginate impression materials. Braz Dent J. 2012;23(4):417-21.

21. International Organization for Standardization. Dental alginate impression material. ISO 1563:1990(E). 2. ed.; 1990.

22. Kawara M, Iwasaki M, Iwata Y, Komoda Y, Inoue S, Komiyama O, et al. Rheological properties of elastomeric impression materials for selective pressure impression technique. J Prosthodont Res. 2015 Oct;59(4):25461. doi: 10.1016/j.jpor.2015.07.002.

23. Carlo HL, Fonseca RB, Gonçalves LS, Correr-Sobrinho L, Soares CJ, Sinhoreti MA. Analysis of filler particle levels and sizes in dental alginates. Mater Res. 2010 Apr/Jun;13(2):261-4.

24. Tan HK, Hooper PM, Buttar IA, Wolfaardt JF. Effects of disinfecting irreversible hydrocolloid impressions on the resultant gypsum casts: part III-Dimensional changes. J Prosthet Dent. 1993 Dec;70(6):532-7.

25. Kambhampati S, Subhash V, Vijay C, Das A. Effect of temperature changes on the dimensional stability of elastomeric impression materials. $\mathrm{J}$ Int Oral Health. 2014 Feb;6(1):12-9. 